\title{
A valorização do labor: crianças e trabalho no Juízo dos Órfãos de Porto Alegre $(\operatorname{Sec} X I X)$
}

\section{José Carlos da Silva Cardozo}

jcs.cardozo@gmail.com

\section{Resumo}

Desde o período colonial até o republicano, as crianças eram encaminhadas ao mundo do trabalho muito cedo, independentemente de sua condição social, cor ou sexo. Este texto, à luz da História Social, analisa a utilização da tutela, atribuída pelo Juízo dos Órfãos de Porto Alegre, no Século XIX, como forma de conseguir crianças e jovens para serviços abusivos, bem como a valorização do adulto que encaminhava os menores de idade para atividades laborais, como forma pedagógica de formação do caráter da criança.

\section{Palavras-chave}

Criança; Tutela; Trabalho; Porto Alegre

\section{The valuation of the labor: children and work in the Court of the Orphans of Porto Alegre (19th century)}

\begin{abstract}
From the colonial period to the republican, children were referred to the world of work very early, regardless of their social status, color or gender. This text, in the light of Social History, analyzes the use of guardianship, attributed by the Court of the Orphans of Porto Alegre in the 19th Century, as a way to obtain children and young people for abusive services, as well as the valuation of the adult who referred the children of age for work activities, as a pedagogical form of character formation of the child.
\end{abstract}

\section{Keywords}

Child; Work; Porto Alegre 
$\mathrm{Na}$ sexta-feira, vinte e oito de abril de 1882, o padrinho de batismo do menor João Faustino Garcia ${ }^{1}$, de nove anos de idade, Joaquim Machado da Silva, deu entrada ao processo de tutela de seu afilhado, afirmando que a mãe do menor, Felicidade Constança Garcia, "não lhe pode dar educação precisa, por ser muito pobre e ter a profissão de criada", tendo informado ainda que o menor já havia estado em sua companhia "e era tratado como filho". Dessa forma, para poder dar ao menor "educação", solicitava a tutela de seu afilhado. No mesmo dia, o pedido foi acolhido pelo Juiz de Órfãos Dr. Bernardo Dias de Castro Sobrinho, e o Termo de Tutela e Compromisso foi assinado no sábado seguinte.

Contudo, nesse mesmo sábado em que havia sido assinado o termo, a mãe do menor João entrou com petição no Juízo dos Órfãos de Porto Alegre, na qual afirmava que era a mãe do menor e que o padrinho de seu filho havia pedido para cuidar da educação do pequeno, pedido que aceitou "na esperança de que seu filho tivesse boa educação". Contudo, "passando um ano, porém, vendo a supl. [suplicante] que seu filho em vez de adiantar-se, atrasava-se cada dia e que apenas servia por criado ${ }^{2}$ de seu padrinho, que nem sequer lhe dava de vestir", ela mandou buscá-lo, "pois, se não o fizesse, ficaria o menor inteiramente perdido", mas Joaquim Silva, "naturalmente por espírito mau" convenceu o menino a sair da casa dela e voltar para a sua; nesse período, ainda requereu a tutoria do menino, "que lhe foi concedida sem dúvida por ter ilaqueado ${ }^{3}$ a boa fé" da Justiça.

Acrescentou, por fim, ao seu pedido que o tutor de seu filho era solteiro e "muito pobre", não possuindo as características e condições necessárias para assumir o cargo de tutor de um menor de idade; assim, ela, " $n a$ qualidade de mãe", pediu a exoneração de Joaquim Silva do cargo de tutor de seu filho João e, para tal função, sugeria o Capitão Carlos Augusto Pereira da Cunha, que, em conversa com ela, aceitava o encargo.

Os autos foram encaminhados ao Juiz de Órfãos no dia primeiro de maio e esse, no mesmo dia, decidiu:

Estando este Juizo informado que o tutor Joaquim Machado da Silva com grande dificuldade poderá promover a educação de seu pupilo, como facilmente pode preencher o cargo de tutor o cidadão P.ra [Pereira] da Cunha, nomeio tutor o cidadão Carlos Augusto P.ra da Cunha, que será intimado, e passe mandado para a entrega do menor.

O importante nessa ação de tutela não é a rapidez, que era uma prática necessária e recorrente diante dos prazos legais impostos (CARDOZO, 2013), mas, sim, a intervenção da mãe do menino, o não questionamento do padrinho quanto às alegações contra sua pessoa, tornando plausíveis as acusações da mãe e, principalmente, a indicação da utilização do menor como "criado" de seu responsável.

O trabalho era visto como uma forma pedagógica de ensinar as crianças. Em estudo sobre o trabalho infantil em Minas Gerais, na primeira metade do século XIX, Horácio Gutiérrez e Ida Lewkowicz verificaram que seria "interessante observar que não havia diferenciação social quanto à inserção das crianças no mundo do trabalho. Livres, escravos e libertos vinculavam-se cedo à produção e no aprendizado das mesmas ocupações” (GUTIÉRREZ; LEWKOWICK, 1999, p. 20); em

\footnotetext{
${ }^{1}$ RIO GRANDE DO SUL. Juízo Districtal da Vara de Orphãos de Porto Alegre. $1^{\text {a }}$ Vara. Petição de tutoria. Proc. $\mathbf{n}^{\mathbf{0}} 2702$ de 1882. [manuscrito]. Porto Alegre, 1882. Localização: APERS.

${ }^{2}$ Destaque nosso.

${ }^{3}$ Ilaquear: "Prender com laço. Enlear, enredar - com sofismas. Fazer cair em logro; enganar. Cair no laço ou no logro" (BRUNSWICK, s/d., p. 640).
} 
Porto Alegre, no final do século XIX, Sandra Pesavento constatou que "quanto à presença das crianças no mercado de trabalho, esta pode ser notada tanto no comércio como nas indústrias" (PESAVENTO, 1994, p. 63). Dessa forma, não era estranha a utilização dos menores em atividades laborais como forma de complementar a renda familiar, de disciplinar seu comportamento ou mesmo de fazê-los aprender um ofício, como foi o caso daqueles menores encaminhados ao Arsenal de Guerra na cidade de Porto Alegre.

Contudo, havia uma linha muito tênue entre o labor como prática pedagógica e o labor como forma de “criadagem disfarçada". Na quinta-feira, dia quinze de maio de 1879, o Subdelegado de Polícia da freguesia de Pedras Brancas, Manoel Soares Sant'Anna, apresentou um ofício ao Juiz Substituto de Órfãos Dr. Epaminondas Brasileiro Ferreira, no qual informava que, no lugar chamado "Sesinha", naquele distrito, havia um menor de idade de nome Victor ${ }^{4}$, cujo pai era desconhecido e que era órfão de mãe.

Sucedeu, porém, que veio a seu conhecimento que aquele menor vivia em companhia de Narciso José Maciel, o qual o "trata como se fosse seu cativo"; assim, mandou a Joaquim Antônio Pinheiro, maior de "19 ou 20 anos" de idade, carpinteiro e, segundo relatos de "pessoas fidedignas", tio de Victor, verificar "o que havia de real a resp.to [respeito] do tratam.to [tratamento] que recebia o seu sobrinho". Ao chegar aquele à casa de Narciso Maciel, ele não se encontrava, e o tio do menino foi "tratado grosseiram.te [grosseiramente]" pela esposa de Narciso, que nem permitiu a Joaquim Pinheiro conversar com o menino, procedimento considerado "condenável" pelo Subdelegado.
Mandou então àquela residência, na ocasião em que Narciso Maciel estava em casa, um Cabo da Força Policial com a finalidade de fazer "averiguações" e intimar a entrega do menor, que foi realizada sem "relutância". O pequeno Victor foi acompanhado de Narciso Maciel para ser interrogado pelo Subdelegado de Polícia, mas, quando foi questionado sobre a forma como era tratado, se sofria "castigos exagerados" e realizava "serviços impróprios para sua tenra idade", respondeu negativamente a todas as indagações; contudo, o Subdelegado considerou "possível, e mesmo provável que este me respondia sob a pressão de insinuações $e$ ameaças"; assim, ordenou que Narciso Maciel deixasse o menor um tempo na delegacia sob sua responsabilidade.

Quando ele saiu, o Subdelegado Manoel Soares Sant'Anna questionou o menor novamente e, " $n a$ ausência de Narciso, ele declarou-me que era massacrado p.la [pela] senhora sogra do mesmo Narciso, $p$. [por] castigos e trabalhos inumerados [sic]; declarando mais que me tinha ocultado a verdade, pelos motivos que eu já suspeitava". O Subdelegado, então, realizou exame no corpo do menino e acrescentou: "observei alguns sinais que parecem ter sido produzidos por serviços".

Assim, ele encaminhava o menor Victor à ciência do Juízo dos Órfãos, não podendo afirmar nada que desabonasse a conduta de Narciso Maciel; sabia apenas que era "homem trabalhador", mas, nas circunstâncias apresentadas, indicava Joaquim Antonio Pinheiro para o cargo, pois este também era trabalhador, sabia ler, escrever e contar "suficientemente" e era "agregado $e$ protegido do Sr. Manoel Alves Pires de Azambuja,

${ }^{4}$ RIO GRANDE DO SUL. Juízo Districtal da Vara de Orphãos de Porto Alegre. $2^{\text {a }}$ Vara. Tutela Ex-officio. Proc. $\mathbf{n}^{\mathbf{0}} 976$ de 1879. [manuscrito]. Porto Alegre, 1879. Localização: APERS.

${ }^{5}$ Destaque nosso. 
charqueador residente no distrito da Barra [do Ribeiro]".

Interessante o parecer do Juiz do caso, realizado no sábado seguinte, dia dezessete: "Atendendo a distancia, despesas de viajem e estada nesta Cidade, não exijo que seja o mesmo apresentado a este Juízo para ser inquirido [o menor Victor], confiando nas indagações a que procedeu a autoridade policial". No mesmo dia, foi lavrado o Termo de Tutela e Compromisso.

Ana Scott e Maria Bassanezi, em relação à criança imigrante paulista, utilizando também documentação proveniente do Juízo dos Órfãos, afirmaram que os menores eram "impotentes", ficando submissos aos "desígnios" dos curadores gerais, juízes e tutores, enfim dos adultos (SCOTT; BASSANEZI, 2005, p. 175). Com base nos casos apresentados até aqui, não podemos concordar em absoluto com a "impotência" dos menores frente aos adultos, pois eles desempenharam, em algumas situações, "papéis" decisivos; contudo, também não podemos atribuir a eles o "papel principal" dentro da instituição, uma vez que são pouquíssimos os casos de tutela em que a participação de um menor de idade foi solicitada dentro de nosso período de análise (entre os anos de 1860 e 1899).

Não havia um regulamento claro quanto à necessidade de se intimar um menor para prestar esclarecimentos perante o Curador Geral ou o Juiz de Órfãos. Nos 952 processos de tutela analisados, não conseguimos mapear, de forma sistemática, quais eram as circunstâncias em que uma criança ou jovem era ou não intimado para ser ouvido; acreditamos que isso tenha decorrido da não disseminação da prática da jurisprudência - atualmente comum e de grande importância no Judiciário -, ou seja, da realização do julgamento de casos semelhantes "sucessivamente do mesmo modo" (SANTOS, 2001, p. 137)
Mas, isso não significa que elas eram "impotentes" frente à situação na qual se deparavam: mesmo não participando diretamente do processo judicial, demonstravam seu descontentamento e suas vontades por meio da indisciplina ou mesmo da fuga da casa do responsável regulado ou imposto. Mas, para compreender isso, necessitamos perceber alguns motivos para a busca pela regularização da guarda de um menor de idade.

\section{Os menores e os adultos}

Os autos de tutela abertos na cidade de Porto Alegre, entre os anos de 1860 e 1899, na quantidade de 952, revelam uma prática contínua na tomada de decisões em face da base orfanológica comum (Ordenações Filipinas que perduraram até a instituição do Código de Menores, em 1927, como regimento legal para assuntos relacionados a guarda e proteção aos menores de idade): os motivos apresentados para se encaminhar um menor de idade para o Juízo dos Órfãos residiam mais nos procedimentos e comportamentos dos adultos do que propriamente nos cuidados efetivos para com a criança.

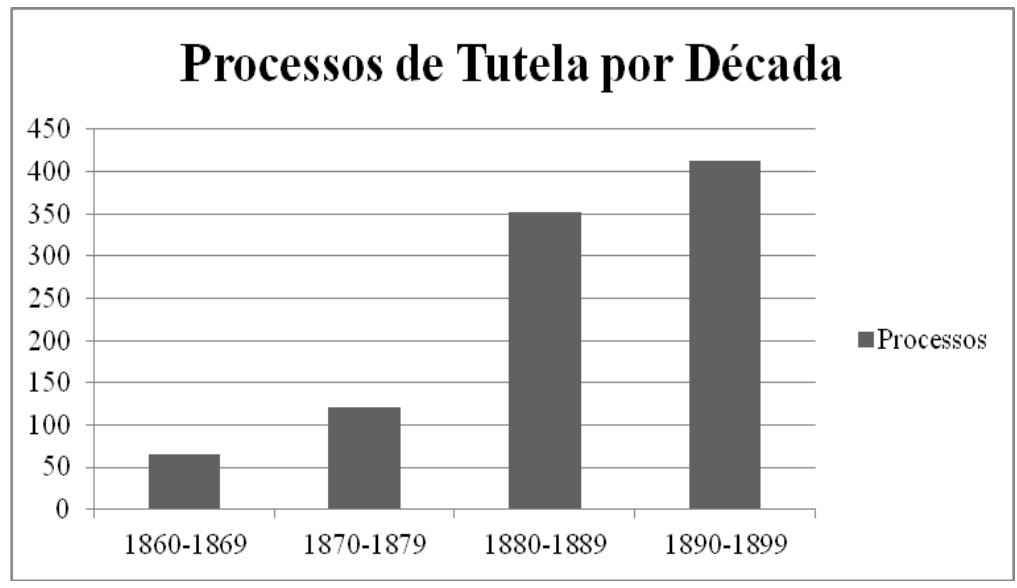

Gráfico 1: Processos de tutela por década, baseado nos processos de tutela de 1860 a 1899, depositados no APERS. Autoria: Elaboração própria. 
Claramente, há uma alteração ao longo dos anos na quantidade de casos abertos na instituição, salto quantitativo, como visto no gráfico 1, atribuído às novas imposições legais de libertação - gradual - do cativeiro escravo (CARDOZO, 2012; CARDOZO; MOREIRA, 2015). Entretanto, o aumento de solicitações de tutela representou uma forma de continuar, em sua grande maioria, com os serviços de alguém em benefício próprio. As ações de tutela abertas em outras localidades $^{6}$, reforçam essa impressão também para a capital do Rio Grande do Sul.

Se, até a década de 60 do século XIX, os processos de tutela possuíam um expediente mais burocrático devido à obrigatoriedade em se nomear um tutor para representar uma criança num processo de inventário ou pensão por falecimento do responsável, a situação veio a alterar-se nos anos seguintes, e uma variedade de motivos eram elencados para pedir ou questionar a guarda de um menor de idade (CARDOZO, 2018). O zelo com as crianças era o motivo inicial para acessar o Juízo dos Órfãos, mas, no decorrer das petições ou desdobramentos da ação judicial, percebemos que o objeto de análise - na grande maioria dos casos - abraçava a prática dos adultos.

Categorias sociais e morais eram constantemente reivindicadas para desqualificar alguém ao cargo de tutor ou retirar a guarda de uma criança. A utilização desse tipo de expediente argumentativo pode estar assentada na impossibilidade de os adultos conseguirem obter êxito no campo legal; Alessandra Rinaldi (2010) esclarece que esse procedimento fazia parte da estratégia dos litigantes quando se divisava que os fatos não possibilitariam o "ganho" da causa. Dessa forma, silenciar as "garantias de direito" e promover a discussão por meio de categorias sociais ou morais (ou mesmo o inverso) apontaria ao que pleiteava a tutela de um menor de idade maiores possibilidades de sucesso na ação.

Por mais que as crianças tivessem vontades e desejos, elas eram percebidas como "páginas em branco", que poderiam ser "escritas" por adultos capacitados para a "redação", ou seja, o que a criança ou jovem se tornaria seria o reflexo das ações daqueles que detivessem sua responsabilidade, imaginário que transpassaria o século XIX e adentraria como visão para as novas lideranças burguesas do Brasil no século XX. Dessa forma, a historiadora Sandra Pesavento nos esclarece que

há toda uma ideia de adestramento dos instintos naturais e de moldagem de corpos e mentes a uma nova ordem que se impõe. Este principio converte, sob certo aspecto, todo 'homem novo' a uma situação de criança: ele é alguém que se intenta conformar as habilidades, inculcar valores, coibir comportamentos e treinar segundo um parâmetro desejado. Nesse raciocínio, quanto mais cedo este processo se iniciasse, maior a probabilidade de êxito teria na obtenção de um 'tipo ideal'. Não é de espantar, pois, que esta estratégia formativa se voltasse para a infância (PESAVENTO, 1995, p. 191).

\section{A "normalidade" do trabalho}

Seguindo o ensejo deste artigo, ao apresentarmos a prática pedagógica do labor (que acabava se transformando em efetivo trabalho e exploração) com o um dos motivos para a tutela de menores de idade, iremos acompanhar o pedido de tutela em que estiveram envoltos os menores Jacintha da Silva Gomes, de de- 
zessete anos de idade, e Manoel da Silva Gomes ${ }^{7}$, com nove anos de idade, ação na qual a jovem Jacintha teve papel decisivo na decisão do Juiz, tendo sido intimada sua presença e exposta a situação em que vivia na primeira família que a havia acolhido.

Sexta-feira, dezenove de agosto de 1898. José Maria Garcia, negociante e casado, apresentou ao Juízo dos Órfãos de Porto Alegre um pedido para tutelar os menores de idade Jacintha da Silva Gomes e Manoel da Silva Gomes, filhos de sua irmã Adelina da Silva Gomes, viúva de Jayme da Silva Gomes. Ele encaminhou sua petição solicitando que, caso o Juiz concordasse com o pedido, ordenasse a expedição de "competente alvará ou Mandado de entrega dos aludidos menores dos quais, uma de nome Jacintha acha-se em companhia da família Durval, e a outra [sic] em companhia dele supl.te [suplicante]".

Na mesma sexta-feira, o Juiz de Órfãos Dr. Antonio Marinho Loureiro Chaves pediu vistas ao Curador Geral de Órfãos, que, na época, era o Dr. José Joaquim de Andrade Neves Netto, que já fora Juiz de Órfãos alguns anos antes, e este respondeu, no sábado seguinte, de forma sucinta e objetiva: "FIAT JUSTITIA $A_{8}$ ", faça-se justiça. No mesmo sábado, os autos foram encaminhados para o Juiz do caso, e esse ordenou: "A fim de resolver sobre a petição de fls.2 [pedido de tutela], mando que os menores a que se refere o suplicante sejam apresentados e ouvidos por este juízo; para o que designo o dia 23 do corrente às 12 horas, feitas as necessárias citações".

Em obediência à ordem do magistrado, os menores foram apresentados, mas somente ela foi ouvida pela Justiça. E ela, quando perguntada sobre a situação em que se encontrava, declarou:

[...] que é órfã de pai e que há oito anos, acha-se em companhia dos irmãos Durval, em cuja casa foi depositada por sua mãe; que vive no Rio de Janeiro; que deseja ardentemente ir para a companhia de seu tio, casado, José Maria Garcia, onde já se acham alguns de seus irmãos também menores, porque contando atualmente a declarante [com] dezessete anos de idade, vive em companhia da família Durval, quase que reclusa, sem passear, sendo-lhe até impedida de chegar a janela, e que não obstante isso, vive gratuitamente sujeita aos trabalhos domésticos da mesma familia, razão por que em tais condições a declarante entende que se acha-se sujeita pelas suas condições a trabalhar, é preferivel que, nesse caso, preste serviços, não a estranhos, mas sim a um parente seu, que nesse caso escolhe de preferência seu tio José Maria, tanto mais que, em companhia deste tem certe$z a$ de viver melhor e com mais conforto; que esses são os seus ardentes desejos. Conquanto não possa alegar maus-tratos na casa em que atualmente vive; que assim age e se manifesta unicamente, como já disse, por viver sopitada na casa Durval.

Com esse longo excerto processual, podemos verificar que a menor trabalhava na casa da família Durval, que Jacintha aceitava e, acreditamos, entendia isso como "normal", uma vez que não tinha pai e que sua mãe morava em outra cidade, ou seja, devido a estar "sujeita pelas suas condições" aos favores que a família Durval lhe prestava, aceitava ter que trabalhar para a família; contudo, acreditava que poderia ter uma vida melhor se fosse morar com o tio, o que não traria a desobrigação de prestar serviços para seu tio, mas, quem sabe, poderia ter maior liberdade, por exemplo,

\footnotetext{
${ }^{7}$ RIO GRANDE DO SUL. Juízo Districtal da Vara de Orphãos de Porto Alegre. $3^{\text {a }}$ Vara. Tutoria. Proc. $n^{\circ} 699$ de 1898 . [manuscrito]. Porto Alegre, 1898. Localização: APERS.9

${ }^{8}$ Maiúsculo no original.

${ }^{9}$ Sentido de vontades reprimidas.
} 
para chegar à "janela" e dar uma espiada no mundo lá fora. No mesmo dia vinte e três de agosto, o Juiz nomeou o tio tutor dos menores, tendo sido, no dia seguinte, lavrado o Termo de Tutela e Compromisso em seu favor.

O desenvolvimento de alguma atividade laboral, como visto anteriormente, era algo valorizado pela Justiça como forma de encaminhar uma criança para tornar -se um adulto responsável. Seguindo orientações morais e sociais, era lícito e desejável que uma menina já colaborasse nos serviços domésticos, assim como os meninos, em atividades externas ao ambiente doméstico (LEWKOWICZ; et al., 2008); dessa forma, é compreensível que a menor Jacintha não tivesse queixas sobre a forma como cuidavam dela, à exceção de algumas proibições que, acreditamos, não causavam dolo.

De igual maneira, enquanto as crianças percebiam o emprego de suas forças em alguma atividade laboral como "normal", alguns adultos ficavam extremamente "desamparados" quando percebiam que sua mão de obra escrava estava em via de alcançar a liberdade por meio das novas diretrizes do Estado nacional, primeiramente com o fim do tráfico internacional de escravos para o país, depois, com a Lei do "ventre livre" e, por fim, com a Abolição da escravidão.

No Rio Grande do Sul, o processo de alforria condicional por tempo de serviço colaborou para a desestruturação do sistema escravocrata na província sulina, pois esse expediente cresceu muito ao longo da segunda metade do século XIX. Paulo Moreira (2003) nos informa que $83 \%$ desses processos centraram-se entre as décadas de 1870 e 1880; desse percentual, perto de $54 \%$ foram realizados entre os anos de 1883 e
1887 (MOREIRA, 2003). Tendo isso em vista, “os senhores de escravos passaram a procurar opções e a redefinir relações já existentes, no sentido de conservar algum controle sobre a mão de obra" (ALANIZ, 1997, p. 19) e, dessa forma, os senhores que tinham crianças pequenas em seus plantéis ou junto de si, acabaram por se valer do expediente da tutela para poderem continuar com algum "criadinho gratuito", como ocorreu no processo de tutela dos menores, "ingênuos"10, Matheus com 13 anos de idade, Emílio, com 11 anos de idade e Carlos $^{11}$, com 7 anos.

Nele, José Caetano Ferraz informou ao Juiz de Órfãos de Porto Alegre que "tendo sua falecida mulher D. Ganularia Adelaide da S. Ferraz comprado, em 21 de outubro de 1876, a escrava Geralda de cor preta, de idade de 33 anos, acompanhada esta de seus filhos", ele, com a morte da esposa, entregou a dita escrava para sua filha Henriqueta Carolina da Silva Ferraz, que passou "carta de liberdade por espaço de sete anos, isto é, com a obrigação [da escrava] de prestar serviços neste espaço de tempo". No embalo da pressão do movimento abolicionista e dos próprios escravos, o pai e a filha passaram, no ano de 1884, três cartas de alforria:

Carta de alforria concedida ao preto José, em 06/08/84, registrada em cartório na mesma data. A carta foi concedida com a condição de o escravo servir por mais 5 anos a seus senhores;

Carta de alforria para a preta crioula Doroteia, em 08/08/84, registrada em cartório em 09/08/84. A carta foi concedida com a condição da escrava servir por mais 5 anos a sua senhora;

Carta de alforria para a negra crioula Geralda, de 41 anos, cozinheira, em 19/08/84, registrada em cartório na mes-

\footnotetext{
${ }^{10}$ Sobre os ingênuos no Rio Grande do Sul, recomendamos ver: CARDOZO (2012) e CARDOZO; MOREIRA (2015).

${ }^{11}$ RIO GRANDE DO SUL. Juízo Districtal da Vara de Orphãos de Porto Alegre. $1^{\text {a }}$ Vara. Tutoria. Proc. $n^{\circ} 2752$ de 1887. [manuscrito]. Porto Alegre, 1887. Localização: APERS.
} 
ma data. A carta foi concedida com a condição da escrava servir por mais 5 anos a seus senhores, "todo o serviço competente com as suas forças, podendo entretanto remir-se desses serviços com a indenização pecuniária, a razão de $200 \$$ anualmente". A escrava estava matriculada sob $n^{\circ} 4321$ da ordem e 1 da relação. ${ }^{12}$

Sendo assim, José Ferraz foi ao Juízo dos Órfãos e pediu a tutela dos meninos, filhos de Geralda, pedido que foi deferido em dois dias após a abertura.

Senhores ou ex-senhores recorrerem a esse expediente para manter uma criança "ingênua" junto a si não foi algo raro no período de nossa análise sobre os processos de tutela; embora a mesma Lei do "ventre livre", de 28 de setembro de 1871, que libertava o ventre escravo e o regulamento da referida $1 \mathrm{e}^{13}$ dessem prerrogativas para os filhos acompanharem suas mães, podemos ver, por outro processo, que representa outras situações semelhantes, a posição dos Juízes de Órfãos quando havia o questionamento dessa determinação.

Assim como na ação anterior, o processo envolvendo os menores Julia e Capitulina ${ }^{14}$, também de condição social "ingênua", foi aberto numa sexta-feira, dia dezesseis de junho de 1882. Na petição inicial, Manoel Gonçalves Júnior afirmou ao Juiz de Órfãos que

[...] tendo vendido a Ernesto Candido da Fontoura uma escrava de nome Florisbella com dois filhos de nome Julia e Capitulina, e que em vista desta venda os referidos menores passaram ao dominio e guarda do comprador segundo o disposto no $\$ 5^{\circ}$ art. $1^{\circ}$ da Lei de $n^{\circ} 2040$ de 28 de setembro de 1871 acontece, porém que o supl. [suplicante] tendo muito desejo de ficar com os filhos da mesma em atenção a grande amizade que sua mulher lhes dedica, e em atenção a essa amizade o comprador abre mão dos serviços dos menores ficando eles já exonerados de qualquer obrigação que por lei lhe fosse imposta para o fim de continuarem vivendo em companhia do supl. [suplicante].

Dessa forma, Manoel Gonçalves Júnior requisitou ao Juiz de Órfãos Dr. Bernardo Dias de Castro Sobrinho a tutela dos dois menores "ingênuos", filhos de sua ex-escrava. No dia quatro de julho, o magistrado veio a pedir vistas ao Curador Geral de Órfãos Dr. Affonso Pereira, que, no mesmo dia da entrega dos autos, afirmaria:

\begin{abstract}
Aos menores de que se trata, não se pode dar tutor, como se requer a fls.2, sem manifesta ofensa do dispositivo na Lei de 28 de 7 bro [setembro] de 1871 art. $1^{\circ} \$ 5$, que terminantemente proibe separar-se da mulher escrava seus filhos menores de doze anos; e nem obsta o consentimento do novo senhor para tal nomeação, porque a ninguém é lícito renunciar ou desistir das obrigações a que está sujeito.
\end{abstract}

Utilizando-se da mesma referência legal, o $\mathrm{Cu}$ rador Geral de Órfãos não acolhia a nomeação do suplicante ao cargo, uma vez que esse vendera a escrava e que o outro senhor deveria arcar com a criação e responsabilidade pelas crianças "ingênuas". Contudo, a decisão do Juiz de Órfãos não compartilhou da mesma interpretação.

\footnotetext{
${ }^{12} 1^{\mathrm{o}}$ Tabelionato de Porto Alegre, Livro 27, folhas 152, 153, 169v. (APERS). Destaque nosso

${ }^{13}$ BRASIL. Decreto $n^{\circ} 5.135$, de 13 de novembro de 1872. Disponível em: <http://www2.camara.leg.br/legin/fed/decret/1824-1899/decreto-5135-13novembro-1872-551577-norma-pe.html>. Acesso em: 20/01/2016.

${ }^{14}$ RIO GRANDE DO SUL. Juízo Districtal da Vara de Orphãos de Porto Alegre. $1^{\text {a }}$ Vara. Autos para Tutoria. Proc. $n^{\circ} 2708$ de 1882 . [manuscrito]. Porto Alegre, 1882. Localização: APERS.
} 
No dia dez, os autos foram entregues ao Juiz, e ests, três dias depois, decidiu:

O art. 2 da Lei $N^{\circ} 2040$ de 1871 dá direito ao senhor da escrava de ceder os filhos desta, que [m] a governa poderá entregar a associações por este autorizada, e o art. 6 do Decreto $N^{o} 5135$ de 1872, que regulamenta a execução da citada lei, acrescentou que as pessoas que forem encarregadas de sua educação, pelo que nomeio a Manoel José Gonçalves Júnior, [...] tutor dos menores referidos [...].

Com essa decisão, o Juiz de Órfãos legitimava a solicitação e ratificava que o ex-senhor poderia ser tutor dos filhos de sua ex-escrava; no dia seguinte ao da decisão, o Termo de Tutela e Compromisso foi assinado.

Com esse último caso, podemos ver claramente posições divergentes entre o Juiz e o Curador Geral de Órfãos, um, argumentando que os filhos deveriam permanecer com a mãe (ainda que ela fosse escrava), e outro, que as crianças poderiam ser postas em tutela. A disputa foi "ganha" por aquele que detinha o maior poder, ou seja, pela única pessoa habilitada a decidir e que, de certa forma, tinha a legitimidade para interpretar a lei, ou seja, o Curador Geral de Órfãos era chamado para dar vistas aos processos, não para decidir sobre eles, prerrogativa que cabia unicamente aos Juízes de Órfãos.

Voltando ao tema desta subsessão, percebemos que possuir um emprego, para um menor, poderia significar mais do que uma privação; poderia ser justamente o inverso: a liberdade e a possibilidade de alcançar au- tonomia. Era o que almejava o menor Pedro José Can$\operatorname{dia}^{15}$, quando pediu a Martinho Rodrigues do Valle para ficar em sua residência. Candia era natural do Paraguai, tinha 15 anos de idade e desejava "algum emprego a fim de obter meios para sua subsistência", e Valle pediu a tutela do menino para encaminhá-lo a um trabalho, pedido que logo foi deferido pelo Juiz de Órfãos.

O labor ou o aprendizado de um ofício, para alguns menores, não era percebido como um problema; todavia, para a grande parte dos adultos, poderia ser visto como uma garantia de auxílio futuro. Como nos adverte Claudia Fonseca,

seria enganador [...] pensar essa relação puramente nos termos de exploração do trabalho infantil, já que os meninos [e as meninas] naturalmente cresceriam $e$ se tornariam adultos. Num contexto onde não existia pensão de velhice, invalidez ou aposentadoria, cada um sabia que, mais cedo ou mais tarde, dependeria de sua prole para um mínimo conforto na velhice (FONSECA, 2008, p. 540).

E foi justamente o que pensou Maria Luiza Schmidt quando encaminhou seu filho Julio Schmidt ${ }^{16}$ para ser tutelado. Ela deu entrada ao processo na segundafeira, dia dezesseis de janeiro de 1888, pedindo um tutor para seu filho de nove anos de idade e, para desempenhar tal função, indicou o Major Domingos José Ferreira Bastos, que era proprietário e se comprometia a "tomar conta do referido menor, mandando-o educar, alimentá-lo e trazê-lo descentemente vestido, a fim de, em tempo oportuno, poder ser útil a si è̀ suplican$\boldsymbol{t} \boldsymbol{e}^{\text {"17 }}$. Enfim, com a tutela, a mãe esperava que seu filho

\footnotetext{
${ }^{15}$ RIO GRANDE DO SUL. Juízo Districtal da Vara de Orphãos de Porto Alegre. 2a Vara. Autos para Tutoria. Proc. $n^{\circ} 923$ de 1871 . [manuscrito]. Porto Alegre, 1871. Localização: APERS.

${ }^{16}$ RIO GRANDE DO SUL. Juízo Districtal da Vara de Orphãos de Porto Alegre. 2a Vara. Tutoria. Proc. $n^{\circ} 95$ de 1888. [manuscrito]. Porto Alegre, 1888. Localização: APERS.

${ }^{17}$ Destaque nosso.
} 
fosse bem cuidado e apreendesse um ofício que pudesse ajudar tanto a ele quanto a ela num futuro. A tutela foi deferida, no dia seguinte, pelo Juiz Dr. Bernardo Dias de Castro Sobrinho.

Considerável número de adultos utilizou como argumento para obter junto ao Estado a tutela de uma criança, a colocação dessa numa atividade laboral. Porto Alegre, entre os anos de 1860 e 1899 , crescia muito em relação a aspectos urbanísticos e sociais, mas isso não acompanhava o crescimento das necessidades da população. Pessoas de várias partes do país e de fora dele vinham para a cidade em busca de melhores condições de ganho e vida, mas esse crescimento desordenado quanto ao número de habitantes acarretava limitações quanto a um trabalho remunerado ou ao pagamento adequado por atividades desempenhadas nesse mister. Dessa forma, havia, como os periódicos da época sugerem (PESAVENTO, 1989; 1994), grande número de desocupados e jornaleiros (pessoas que trabalhavam por jornadas ou empreitadas) e, não havendo uma renda regular assegurada, a colocação de menores de idade em alguma atividade laboral poderia significar uma complementação ao orçamento doméstico.

Mas o que Maria Luiza Schmidt não podia imaginar nessa equação que multiplicaria suas chances de ter um alívio no orçamento doméstico e, talvez, uma boa velhice (com a possível ajuda financeira de seu filho) foi o fato de o pequeno Julio não retribuir da forma esperada aos préstimos de seu tutor. Em vinte e três de março de 1892, o processo voltaria às mãos do Juiz com a seguinte demanda de Domingos Bastos:

Domingos José Ferreira Bastos, morador nesta cidade, vem dizer-vos: que por despacho deste juízo, foi o suplicante nomeado tutor do menor Julio Schmidt, filho de Maria Luisa Schmidt; que o suplicante até a presente data tem comprido fielmente com os deveres que lhe impõe seu cargo junto ao referido menor; que ultimamente, este se tem afastado completamente em obedecer ao suplicante, não querendo por forma alguma sujeitar-se a um trabalho honesto em que possa encarreirar-se ${ }^{18}$; que tendo seu tutelado atingindo a idade de 13 anos, e não sendo possivel o suplicante contê-lo no modo irregular que está procedendo, vem requerer a V.S. [vossa senhoria] uma providencia de forma a evitar-se que ele venha de um todo perderse e para isso lembra destiná-lo a escola de Aprendizes Marinheiros, onde existe severa disciplina e poderá esse menor regenerar-se sendo útil a si e a sociedade.

No mesmo dia, o Juiz de Órfãos Dr. Francisco Marques da Cunha mandou que o chefe respectivo fosse informado, tarefa que o Escrivão de Órfãos João Baptista de Sampaio cumpriu no dia seguinte ao encaminhar ofício do Juízo dos Órfãos ao $1^{\circ}$ Tenente Delegado do Capitão do Porto. Infelizmente, o processo silencia a partir desse ponto, mas, por meio desse pleito, podemos aventar o que estava por detrás das solicitações de tutela, bem como dos encaminhamentos para o aprendizado de um ofício.

Como bem mencionou Claudia Fonseca, citada anteriormente, havia uma expectativa de um retorno econômico por parte dos adultos quando esses encaminhavam seus pequenos para alguma atividade laboral, porém muitos menores acabavam demonstrando seu descontentamento com tal situação por meio da indisciplina. Da mesma forma que o trabalho infantil era considerado "normal" ou "aceitável" (do qual receberia certo conforto e aprendizagem), havia aquele conside-

\footnotetext{
${ }^{18}$ Destaque nosso.
} 
rado "inaceitável", em que os adultos exploravam os pequenos como "criadinhos gratuitos", sobrecarregando -os de trabalho e sonegando-lhes alimentação adequada (FONSECA, 2006).

Boa parte dos adultos que tutelavam menores de idade, principalmente se eles já fossem maiores de 7 ou 8 anos, não queria uma criança para criar, mas sim um adulto em "miniatura", que pudesse ajudar, ou mesmo, que já pudesse trabalhar de forma regular; o não atendimento a essas expectativas poderia acarretar um desfecho como o que ocorreu no processo acima, em que o tutor não querendo mais ficar com o menor de idade, desejou enviar seu tutelado para uma escola da marinha, pois lá o menino Julio encontraria "severa discipli$n a "$.

\section{Considerações finais}

Neste artigo, pudemos acompanhar alguns casos que são exemplos de tantos outros processos de tutela, nos quais as crianças que eram encaminhadas ao Juízo dos Órfãos de Porto Alegre vinham pelos mais variados motivos, dentre eles a utilização delas em alguma ativi- dade laboral. Muito adultos se valeram da compreensão social de que as atividades laborais eram uma forma pedagógica de formação do caráter da criança para conseguirem "criadinhos gratuitos", explorando as crianças, os adolescentes e os jovens que necessitassem de um responsável legal.

Não havia uma prática (ou regulamento) que obrigasse os operadores do direito a intimarem as crianças a prestar esclarecimento sobre a situação em que estavam enredadas. Algumas foram chamadas, outras não (não conseguimos entender o porquê, uma vez que eram casos semelhantes), mas o certo é que havia esse recurso, que, na maioria dos processos de tutela do Juízo dos Órfãos de Porto Alegre, não foi acionado, talvez para que fosse respeitado o prazo legal de conclusão do processo que, pela normativa, era de 30 dias (CARDOZO, 2013).

Mesmo assim, ouvir de forma regular a posição dos menores de idade poderia ter contribuído para evitar conflitos e dissabores tanto para os adultos quanto para as crianças, como as situações envolvendo a exploração de seu serviço. 


\section{Referências Bibliográficas}

ALANIZ, Anna Gicelle García. Ingênuos e libertos: estratégias de sobrevivência familiar em épocas de transição (1871-1895). Campinas/SP: CMU/UNICAMP, 1997

AZEVEDO, Gislane Campos. De Sebastianas e Geovannis: o universo do menor nos processos dos juízes de órfãos da cidade de São Paulo (1871-1917). Dissertação (Mestrado em História), Pontifícia Universidade Católica de São Paulo, SP, 1995.

BRUNSWICK, Henrique. Novo dicionário ilustrado da língua portuguesa. 3. ed. Lisboa/PT: Empresa Literária Fluminense: s/d.

CARDOZO, José Carlos da Silva. "Como se fosse meu filho”? As crianças e suas famílias no Juízo dos Órfãos de Porto Alegre (Século XIX). São Leopoldo/RS: Oikos/Editora UNISINOS, 2018.

CARDOZO, José Carlos da Silva. A tutela dos filhos de escravas em Porto Alegre. Revista Latino-Americana de História, v. 1, p. 88-98, 2012.

CARDOZO, José Carlos da Silva. Enredos tutelares: o Juízo dos Órfãos e a atenção à criança e à família portoalegrense no início do século XX. São Leopoldo/RS: Oikos/Editora UNISINOS, 2013.

CARDOZO, José Carlos da Silva; FLECK, Eliane Cristina Deckmann; SCOTT, Ana Silvia Volpi. Juízo dos Órfãos: a instituição e seus funcionários. In: MOREIRA, Paulo Roberto Staudt; et. al.) Org .(.Instituições e práticas de controle social: perspectivas de pesquisa. São Leopoldo/RS: Oikos/Editora UNISINOS, 2016, p. 84111.

CARDOZO, José Carlos da Silva; MOREIRA, Paulo Roberto Staudt. Anjos marcados: o batismo dos filhos do ventre livre (Porto Alegre/RS - 1871-1888). Revista Brasileira de História \& Ciências Sociais, v. 7, p. 80-94, 2015 .

FONSECA, Claudia. Caminhos da adoção. 3. ed. São Paulo: Cortez, 2006.

FONSECA, Claudia. Ser mulher, mãe e pobre. In: DEL PRIORE, Mary (Org.); BASSANEZI, Carla (Coord. de Textos). História das mulheres no Brasil. 9. ed. São Paulo: Contexto, 2008.

FRANCISCO, Raquel Pereira. Laços da senzala, arranjos da Flor de Maio: relações familiares e de parentesco entre a população escrava e liberta - Juiz de Fora (1870-1900). Dissertação (Mestrado em História), Universidade Federal Fluminense, Niterói, RJ, 2007.

GEREMIAS, Patrícia Ramos. Ser “ingênuo” em Desterro/SC: A lei de 1871, o vínculo tutelar e a luta pela manutenção dos laços familiares das populações de origem africana (1871-1889). Dissertação (Mestrado em História), Universidade Federal Fluminense, Niterói, RJ, 2005.

GUTIÉRREZ, Horácio; LEWKOWICZ, Ida. Trabalho infantil em Minas Gerais na primeira metade do século XIX. Lócus: revista de história, UFJF. V. 5 n.2, jul/dez, 1999, p. 9-21.

LEWKOWICZ, Ida; et al. Trabalho compulsório e trabalho livre na história do Brasil. São Paulo: Editora UNESP, 2008.

MOREIRA, Paulo Roberto Staudt. Os cativos e os homens de bem: experiências negras no espaço urbano. Porto Alegre: EST Edições, 2003.

PAPALI, Maria Aparecida C. R. Escravos, libertos e órfãos: a construção da liberdade em Taubaté (1871-1895). São Paulo: Annablume; FAPESP, 2003.

PESAVENTO, Sandra Jatahy. A emergência dos subalternos: trabalho livre e ordem burguesa. Porto Alegre: Editora da Universidade/UFRGS; FAPERGS, 1989. 
PESAVENTO, Sandra Jatahy. Os pobres da cidade: vida e trabalho (1880-1920). Porto Alegre: Editora da Universidade/UFRGS, 1994.

PESAVENTO, Sandra Jatahy. Os pobres da cidade: vida e trabalho (1880-1920). Porto Alegre: Editora da Universidade/UFRGS, 1994.

PESAVENTO, Sandra Jatahy. Os trabalhadores do futuro. O emprego do trabalho infantil no Rio Grande do Sul da República Velha. História, São Paulo, n. 14, p. 189-201, 1995.

PINHEIRO, Luciana Araújo. A civilização do Brasil através da infância: propostas e ações voltadas à criança pobre nos anos finais do Império. Dissertação (Mestrado em História), Universidade Federal Fluminense, Niterói, RJ, 2003.

RINALDI, Alessandra de Andrade. Passionalidade, patologia e vingança: um estudo sobre mulheres, crimes e acesso à Justiça (1890-1940). In: SCHUCH, Patrice; FERREIRA, Jaqueline. (Orgs.). Direitos e ajuda humanitária: perspectivas sobre família, gênero e saúde. Rio de Janeiro: Editora Fiocruz, 2010, p. 245-275.

SANTOS, Washington dos. Dicionário jurídico brasileiro. Belo Horizonte/MG: Del Rey, 2001.

SCOTT, Ana Silvia Volpi; BASSANEZI, Maria Silvia C. No fundo do baú: procurando as crianças imigrantes nas fontes documentais paulistas. In: RADIN, José Carlos (Org.). Cultura e identidade italiana no Brasil. Joaçaba/SC: UNOESC, 2005.

TEIREIRA, Heloísa Maria. A não-infância: crianças como mão de obra em Mariana (1850-1900). Tese (Doutorado em História), Universidade de São Paulo, 2007.

ZERO, Arethuza Helena. O preço da liberdade: caminhos da infância tutelada - Rio Clara (1871-1888). Dissertação (Mestrado em História), Universidade Estadual de Campinas, Campinas, SP, 2004.

Submissão: 29/04/2018 Aceite: 02/09/2018 